\title{
Sobre cor, poesia, docência e Ensino de Ciências
}

\author{
Nadson Fernando Nunes da Silva \\ Sandra Nazaré Dias Bastos
}

Dara ensinar a vida é preciso dissecar, taxidermizar, classificar e
preservar em álcool. A vida então, estática, descolorida, esquadrinhada está morta! Ligados no "automático" saímos repetindo (ad aeternun) verdades incontestáveis que povoam "os caminhos bem ordenados do Jardim da Educação”. Para pensar a docência de outra forma uma provocação é lançada: Precisamos seduzir, encantar... O professor deverá lançar pistas, iscas para que o aluno possa entrar em sintonia e se deixe envolver e se afetar pelos signos e daí se lançar à possibilidade de estabelecer uma relação amorosa com aquilo que deseja aprender. A partir dessa ideia um desafio: como eu gostaria de ver/experimentar/experenciar a docência? Com que cores gostaria de ver pintados os conteúdos de Ciências? A simplicidade da poesia de Manoel de Barros rapidamente invadiu nossas folhas de papel. "As coisas não querem mais ser vistas por pessoas razoáveis: Elas desejam ser olhadas de azul", e um professor-menino materializa-se. Seu semblante sereno nos mostra que ele ainda não foi corrompido pelas "ideias feitas e pelas belas (e falsas!) verdades evidentes". De sua boca não saem definições e palavras impronunciáveis. Adormecido (estaria sonhando?) parece querer nos dizer: "Para ver em azul é preciso desnudar as coisas de seus significados gastos, impenetráveis, carcomidos. Para conhecer é preciso antes "desconhecer", desacostumar as coisas de seus vícios. Fazê-las delirar dando-lhe significações novas, inusitadas. É preciso desformar o mundo, tirar da 
natureza as naturalidades”. No processo de ver, rever e transver uma árvore desvencilha-se de sua anatomo-fisiologia vegetal uniforme e estática para ser surpreendida em uma profusão de cores. No lugar de setas que indicam o direcionamento dos monótonos fluxos das seivas bruta e elaborada, traços delicados indicam que os caminhos possíveis estendem-se para além da verticalidade raiz/copa de que nos falam os livros. As penas deixam de ser "estruturas mortas de queratina originadas a partir da derme" para transformarem-se em coloridas e graciosas bailarinas. A borboleta se liberta de seu casulo (e do codinome Lepidóptera) e se lança solta no espaço espalhando poesia e delicadeza. A moça negra se veste de azul, solta a cabeleira encaracolada e pinta a boca de vermelho para anunciar que seu cabelo não é ruim e que "mulata" é um termo que não consta em seu vocabulário. Nesse caminho inventa-se uma docência que, ao se aventurar a mudar a função das palavras, se propõe a escutar a voz dos passarinhos e a desenhar o cheiro das árvores. Uma docência revestida de cores que podem ser escutadas, capaz de transformar nossas aulas em um jogo de sensações inesperadas que leve a desconfiar dos conceitos e significados que enclausuram uma origem das coisas. Uma docência que faça da sala de aula um espaço de liberdade no qual poesia, cores, flores e emoções se encontram não para ensinar certezas, mas para desatar aquilo que une a linguagem às coisas e investe na desnaturalização do olhar acostumado a tantas normalidades. Uma docência que em processo de fuga dos manuais didáticos se entregue ao desafio de se inventar cotidianamente como uma obra de arte. 

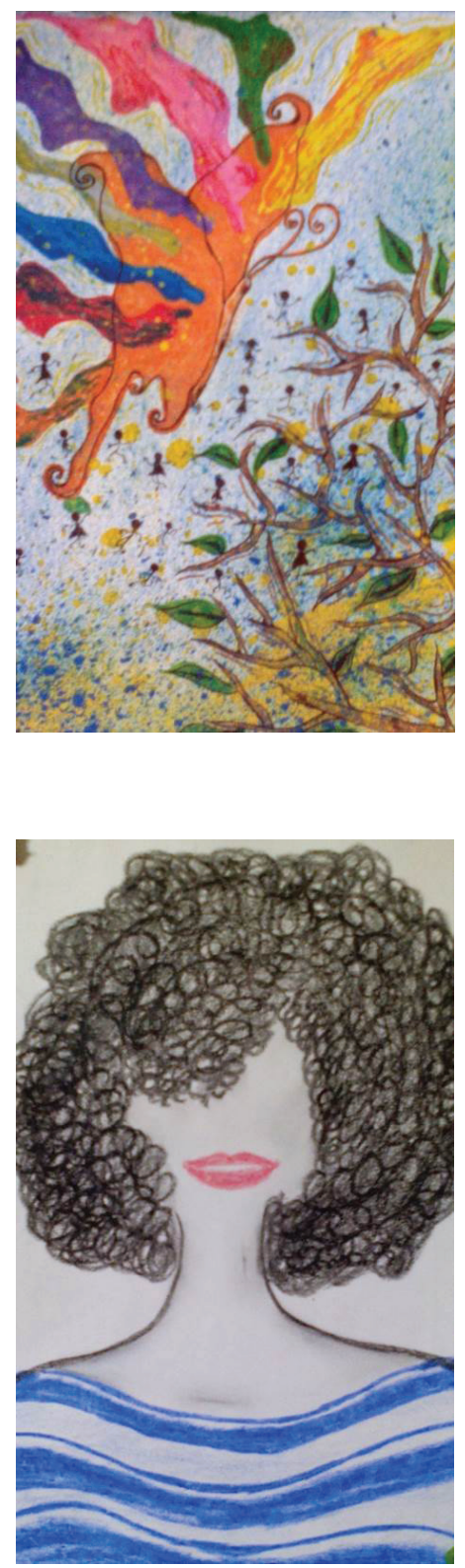
52 EXPERIM E N T $\bigwedge$ R T Ano 2-n. 3-jul./dez. 2016-ISSN 2526-7736

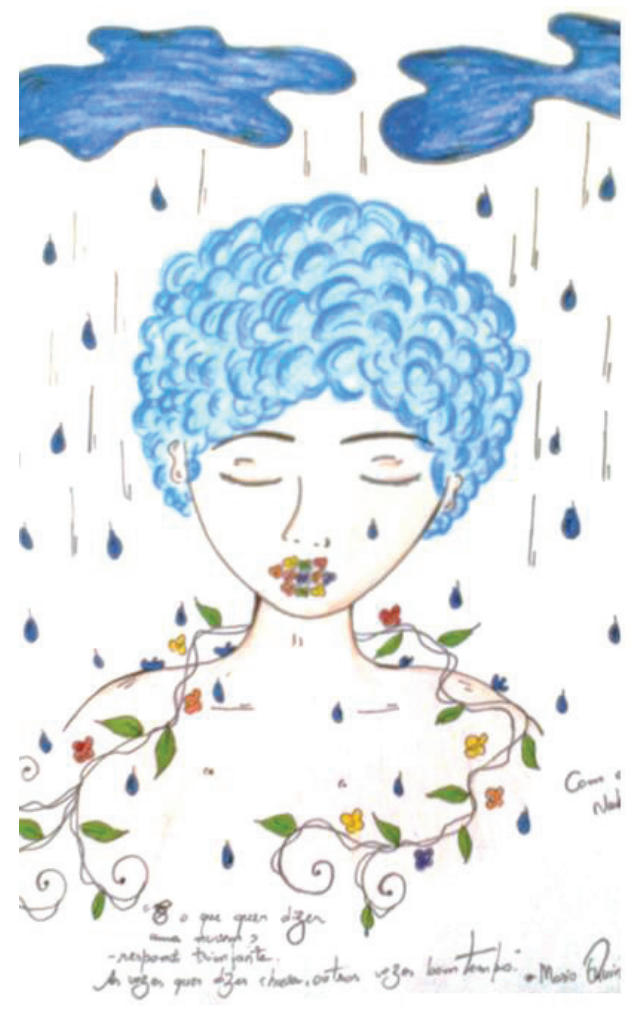




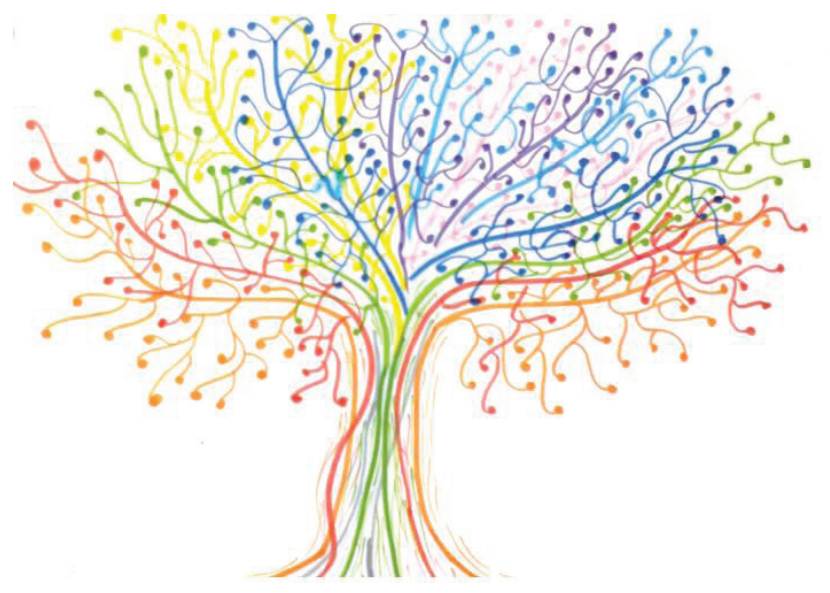


54 EXPERIM E N T $\bigwedge$ R T Ano 2-n. 3-jul./dez. 2016- ISSN 2526-7736

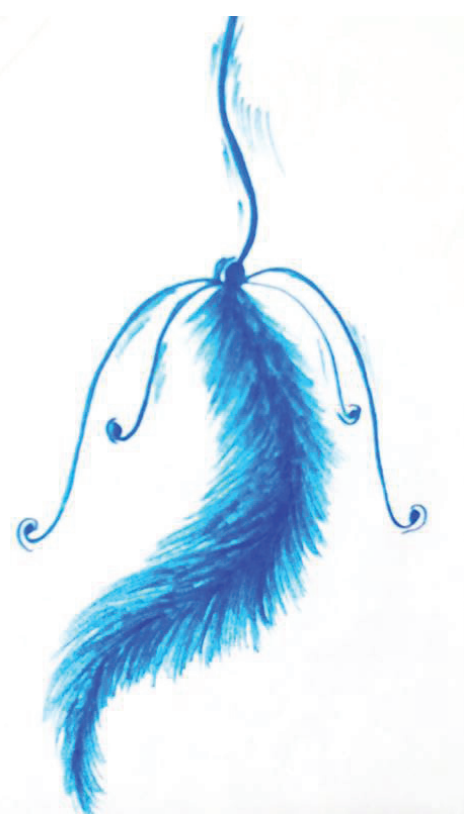

Nadson Fernando Nunes da Silva é discente do curso de Licenciatura em Ciências Naturais da Universidade Federal do Pará, campus de Bragança. Bolsista PAPIM/PROEG. E-mail: nadsonfernando14@gmail.com

Sandra Nazaré Dias Bastos é professora da Universidade Federal do Pará, campus de Bragança; doutora em Educação em Ciências, pela UFPA. E-mail: sndbastos@yahoo.com.br 